\title{
Smiling odontoid
}

A 16 year old woman was a restrained rear seat passenger in a single vehicle high speed motor vehicle collision. She had a transient loss of consciousness, but when paramedics arrived, her Glasgow coma scale (GCS) score was 14. After extrication from the vehicle, the patient complained of upper cervical spine pain; a rigid cervical collar was placed and the patient was fully immobilised on a long spine board. The patient, along with the other occupants of the vehicle, were flown by helicopter from the scene of the accident to our trauma centre. Primary and secondary surveys showed a neurologically intact patient with a GCS of 15, with continued complaints of upper cervical pain. Lateral cervical spine films showed type II traumatic spondylolisthesis of C2 (hangman's fracture). The patient underwent CT of the head (normal) and CT of the upper cervical spine. In addition to the fracture, the scan disclosed a second finding: a "smiling face" within the odontoid process. The two "eyes" and "mouth" represent areas of trabecular bone whereas the remainder of the "face" consists of more dense cortical bone invaginating into the less dense trabecular bone. A non-pathological finding, the "smile" became visible when axial cuts were made through the apex of the dens. The patient subsequently underwent closed reduction of her fracture and placement in halovest fixation. After 2 days, she was discharged home. Since noticing this amusing normal variant, we have seen other "faces" in axial CT through the odontoid process, but none as clear as the case presented here.

\section{K L STEVENSON W C WELCH}

Department of Neurological Surgery, University of Pittsburgh Medical Center, Presbyterian University Hospital, Suite B-400, 200 Lothrop Street, Pittsburgh, PA 15213-2582, USA

Correspondence to: Dr K L Stevenson klstevenson@msn.com
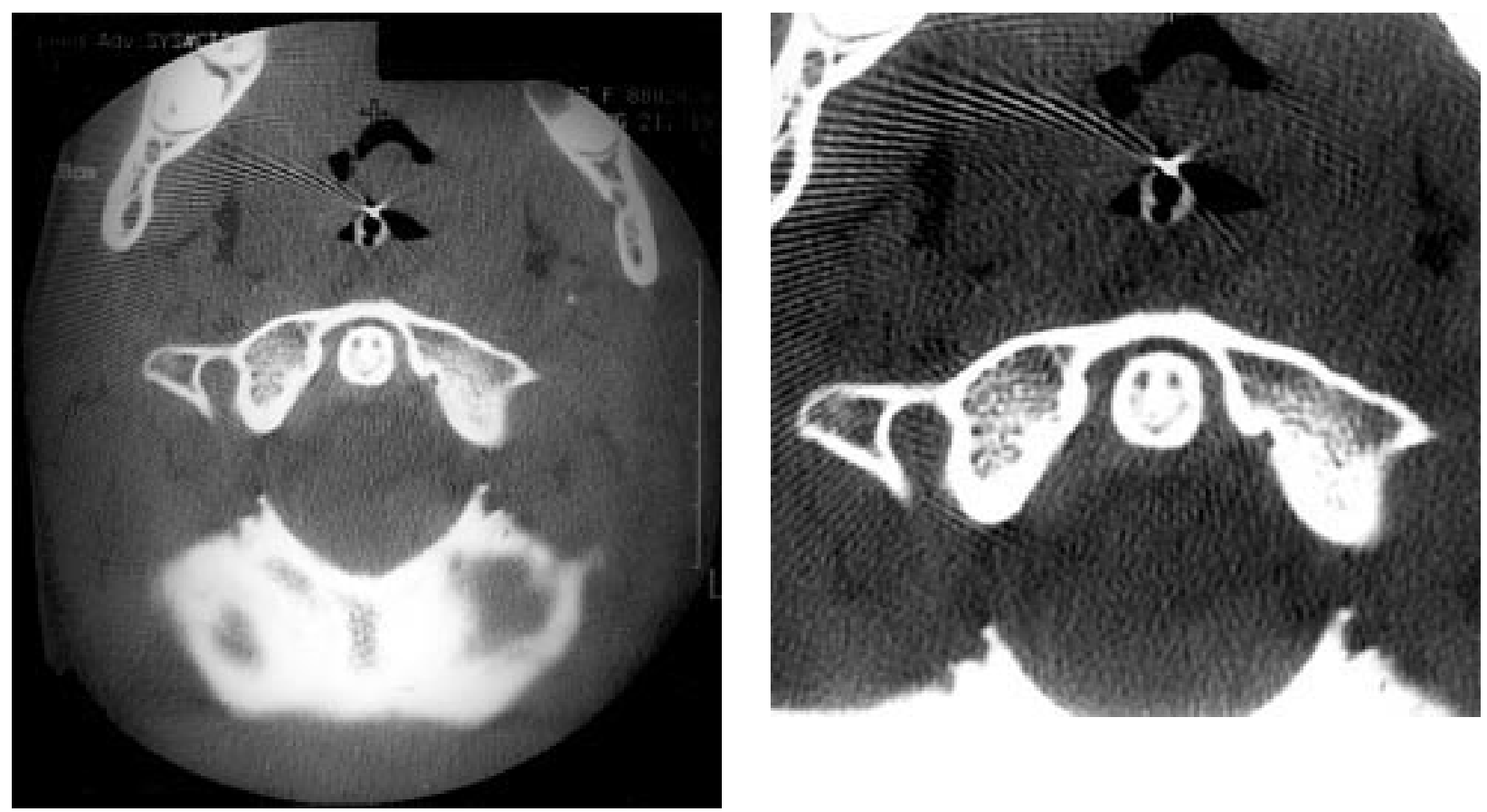